\title{
Upper-mesospheric temperatures measured during intense substorms in the declining phase of the January 2005 solar proton events
}

\author{
H. Nesse Tyssøy ${ }^{1,2}$, D. Heinrich ${ }^{1}$, J. Stadsnes ${ }^{2}$, M. Sørbø ${ }^{2}$, U.-P. Hoppe ${ }^{1}$, D. S. Evans ${ }^{3}$, B. P. Williams ${ }^{4}$, and F. Honary ${ }^{5}$ \\ ${ }^{1}$ Norwegian Defence Research Establishment, Kjeller, Norway \\ ${ }^{2}$ University of Bergen, Bergen, Norway \\ ${ }^{3}$ NOAA Space Environment Center, Boulder, USA \\ ${ }^{4}$ NorthWest Research Associates/Colorado Research Associates Division, Boulder, USA \\ ${ }^{5}$ Lancaster University, Lancaster, UK
}

Received: 7 August 2007 - Revised: 19 December 2007 - Accepted: 21 January 2008 - Published: 1 September 2008

\begin{abstract}
Temperature measurements from the ALOMAR Weber Na lidar together with cosmic radio noise absorption measurements from IRIS and particle measurements from NOAA 15,16 and 17 are used to study effects of geomagnetic activity on the polar winter upper-mesospheric temperature. On 21-22 January 2005 we have $14 \mathrm{~h}$ of continuous temperature measurement with the $\mathrm{Na}$ lidar coinciding with strong geomagnetic activity in the declining phase of one of the hardest and most energetic Solar Proton Event (SPE) of solar cycle 23. According to measurements by the imaging riometer IRIS in northern Finland, the temperature measurements coincide with two periods of increased cosmic radio noise absorption. Particle measurements from the three satellites, NOAA 15, 16 and 17 that pass through and near our region of interest confirm that the absorption events are probably due to particle precipitation and not due to changes in e.g. the electron recombination coefficient.

The measured temperature variation at 85 and $90 \mathrm{~km}$ is dominated by a 7.6-h wave with downward phase propagation and a vertical wavelength of approximately $10 \mathrm{~km}$. Assuming that the wave is due to a lower altitude source independent of the particle precipitation, we do not find any temperature modification that seems to be related to the absorption events. The average temperature is larger than expected above $90 \mathrm{~km}$ based on MSIS and the monthly mean from falling spheres, which could be due to particle precipitation and Joule heating prior to our measurement period. There is also a possibility that the identified wave phenomenon is an effect of the geomagnetic activity itself. Earlier studies have reported of similar wavelike structures in wind observations made by the EISCAT VHF radar during SPEs, and found it
\end{abstract}

Correspondence to: H. Nesse Tyss $\varnothing \mathrm{y}$

(hilde.nesse@ift.uib.no) conceivable that the wave could be excited by the effect of energetic particles precipitating into the mesosphere.

Keywords. Atmospheric composition and structure (Pressure, density, and temperature) - Ionosphere (Ionosphereatmosphere interactions; Particle precipitation)

\section{Introduction}

The upper mesosphere and lower thermosphere are the least known regions in our atmosphere when considering the energy budget. A large number of parameters influence the energy balance. Electromagnetic radiation from the sun, particle precipitation, Joule heating, atmospheric waves, winds, turbulence, chemical reactions, infrared cooling, photoelectrons and heat conduction do all play an important part in the cooling and heating processes. The energy balance gets even more complicated when considering their internal interactions, and that some of the processes are able to heat the atmosphere as well as to cool it, depending on the specific conditions present (Offermann, 1985; Roble, 1995).

During geomagnetic disturbances the atmosphere will experience an energy increase from particle precipitation and Joule heating (e.g. Banks, 1977, 1979; Rees et al., 1983). At the same time, the particle precipitation will influence the composition of the atmosphere through ionization, dissociation, and excitation. Changing the gas composition will also change the chemical heating rates, and the infrared cooling rates. The plasma flow, controlled by the electric field, will together with the new temperature gradients change the neutral winds, which in turn also modifies the temperatures and gas composition in the upper atmosphere. In particular, Solar Proton Events (SPEs) are predicted to have a significant

Published by Copernicus Publications on behalf of the European Geosciences Union. 

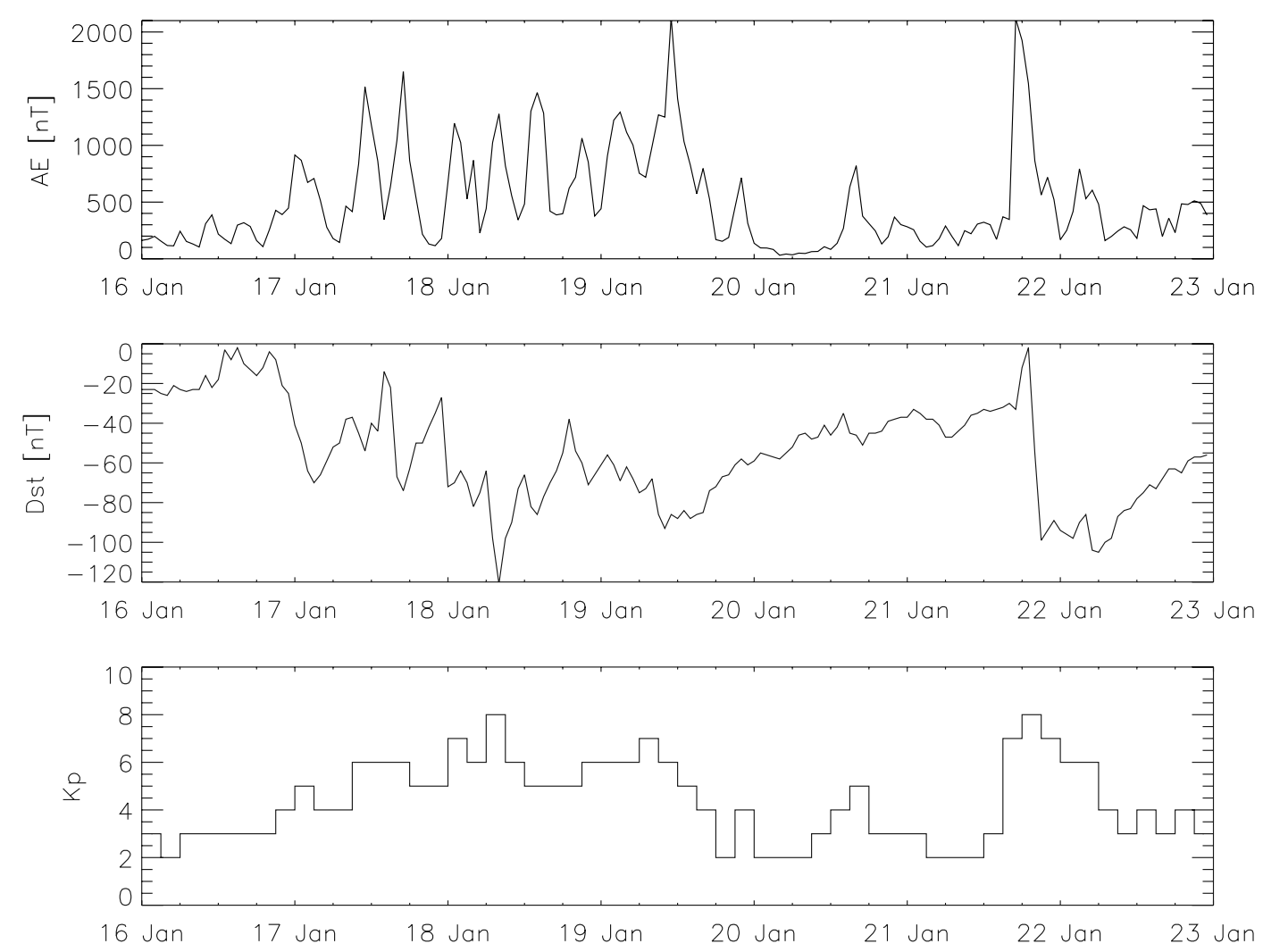

Fig. 1. Hourly AE and $D_{s t}$ (upper and middle plot), and 3-hourly $K_{p}$ (bottom plot) for the period from 16-22 January 2005.

impact on the upper and middle atmosphere due to highly energetic particles precipitating in the atmosphere (Banks, 1979; Jackman and McPeters, 1985; Roble et al., 1987; Reid et al., 1991; Zadorozhny et al., 1994; Jackman et al., 1995, 2007; Krivolutsky et al., 2006). These studies are mostly based on model calculations that use measurements of e.g. particle fluxes and electric fields, and not actual temperature measurements. There is also a group of studies suggesting a temperature enhancement associated with SPEs or other particle precipitation events partly based on observations of the disappearance of noctilucent clouds and polar mesospheric summer echoes during SPEs (Kubo et al., 2003; von Savigny et al., 2007), or observations of enhanced upward winds in the upper mesosphere or lower thermosphere (Peterherych et al., 1985; Price and Jacka, 1991). Efforts to measure the temperatures directly during SPEs have been made by e.g. Zadorozhny et al. (1994). Based on rocket measurement they found a temperature decrease from the stratopause up to approximately $70 \mathrm{~km}$. The Microwave Limb Sounder onboard the Aura satellite detected a temperature increase at $85 \mathrm{~km}$ altitude coinciding with the January 2005 SPE (von Savigny et al., 2007). Pancheva et al. (2007) found a significant temperature drop of approximately $25 \mathrm{~K}$, detected by the meteor radar at Andenes at an altitude of about $90 \mathrm{~km}$ during one of the October 2003 SPEs. The contradictory results in the upper mesosphere may be due to the complexity of the energy budget. Additionally, there are very few studies where both the upper mesospheric temperature and the local particle precipitation are observed.

On 16 January 2005 a series of Solar Proton Events (SPEs) began. A SPE starts as emission of high energy charged particles on the surface of the sun associated with solar flares and coronal mass ejections (CME). Energetic particles are also generated in the interplanetary medium by interactions with shocks. The particle flux is dominated by protons, accompanied by heavier ions and electrons. Guided by the interplanetary and Earth's magnetic field, the energetic particles precipitate their energy in both the upper and middle atmosphere in the polar cap and the auroral zone. The X7 flare and CME on 20 January marked the start of the so far hardest and most energetic SPE of Cycle 23. The $>10 \mathrm{MeV}$ proton flux peaked on 20 January UTC and showed an enhanced level until about 18:00 UT 22 January. Additionally, the declining phase of the SPE (21-22 January) is accompanied by an intense geomagnetic storm and strong substorm activity. The 3-hourly $K_{p}$ index was 7 and 8 late on 21 January accompanied by strong deflection in both the $D_{s t}$ and AE index as shown in Fig. 1.

From about 18:00 UT on 21 January until 07:00 UT on 22 January 2005 we measured upper-mesospheric temperatures above Andøya in Norway using the ALOMAR Weber Na lidar. We monitored the particle precipitation near Andøya by 
combining particle measurements on board NOAA 15, 16 and 17 together with cosmic radio noise absorption observations by the Imaging Riometer for Ionospheric Studies (IRIS) in Kilpisjärvi, Finland. These measurements give us a valuable opportunity to search for possible temperature effects caused by particle precipitation during a relatively strong geomagnetic event. Since very few studies consider simultaneous observations of both upper mesospheric temperature and local particle precipitation, the following analysis is important for our understanding of the energy budget in this region. The instrumentation used is presented in Sect. 2, while the measurements and associated discussion are presented in Sect. 3. In Sect. 4 we will evaluate possible theories explaining our results.

\section{The instrumentation}

\subsection{The ALOMAR Weber Na lidar}

The ALOMAR Weber Na lidar is a sodium (Na) fluorescence lidar (She et al., 2002; Vance et al., 1998; Arnold and She, 2003). This instrument is used to determine the $\mathrm{Na}$ density profiles, as well as atmospheric temperature and wind from about 80 to $100 \mathrm{~km}$ by remote spectroscopy. The instrument is part of the Arctic Lidar Observatory for Middle Atmosphere Research (ALOMAR), located at Andøya in Norway $\left(69.2^{\circ} \mathrm{N}, 16.0^{\circ} \mathrm{E}\right)$.

The lidar system emits light at three known frequencies in sequential order. A small fraction of the emitted light is resonantly scattered by atmospheric $\mathrm{Na}$ atoms, which exist in the mesopause region due to meteor ablation. The measured intensities are fitted to the theoretical shape of the spectrum of the $D_{2 a}$ transition of the $\mathrm{Na}$ atom, which depends on the atmospheric temperature (Doppler broadening) and the lineof-sight wind (Doppler shift). The Na density is proportional to the ratio of the observed count rates in the $\mathrm{Na}$ layer and the Rayleigh reflected signal from the stratosphere (Fricke and von Zahn, 1985; Heinrich et al., 2005).

\subsection{IRIS}

The Imaging Riometer for Ionospheric Studies (IRIS) in Kilpisjarvi in northern Finland $\left(69.05^{\circ} \mathrm{N}, 20.79^{\circ} \mathrm{E}\right)$ measures ionospheric absorption of cosmic radio noise at 38.2 MHz in 49 beams (Browne et al., 1995). The projection of these beams at $90 \mathrm{~km}$ spans the area of $67.8^{\circ}-70.2^{\circ} \mathrm{N}$, and $17.8^{\circ}-23.8^{\circ} \mathrm{E}$, as seen in Fig. 2. None of the riometer beams overlaps with the ALOMAR Weber Na lidar, but beam 8, 15 and 22 might be representative for the absorption above Andøya.

Cosmic radio noise is of galactic origin and is a known quantity (varying with e.g. location and time of day and year), so that any deviation in the expected signal observed on the ground is due to changes in the ionospheric absorption. There are several sources causing ionization in the D-

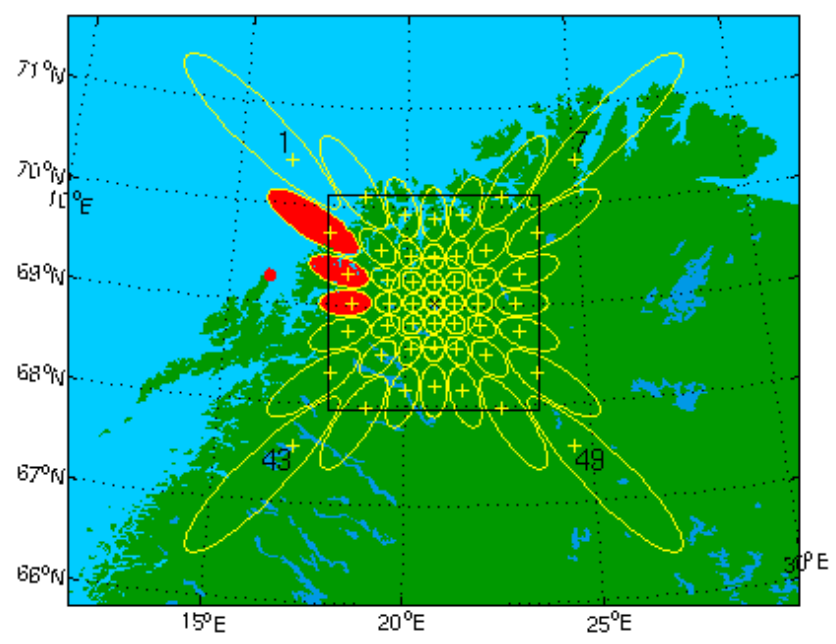

Fig. 2. The beam projection for the 49 beams of IRIS at $90 \mathrm{~km}$ (Map: S. Marple, Lancaster University). None of the riometer beams overlap with the ALOMAR Weber Na lidar (marked as a red dot), but beam 8,15 and 22 (coloured red) might be representative for the absorption above Andøya.

region, such as solar electromagnetic emissions, solar protons and energetic electrons. The ionospheric effects of SPE were already identified in the 1950 s, after a large solar flare was followed by radio communication blackout due to the enhancement of electron densities, thus these events were named polar cap absorption (PCA) in the field of radio physics.

There have been several attempts to derive an empirical relationship between the cosmic radio noise absorption and the precipitating flux of the solar protons (e.g. Kavanagh et al., 2004; Hargreaves, 2005; Rodger et al., 2006). One challenge is the electron recombination coefficient and its sensitivity to the solar zenith angle. During night-time the free electrons are removed at the lower altitudes by attachment to oxygen. Hargreaves (2005) showed that the altitudes from about $45-65 \mathrm{~km}$ typically account for $80 \%$ of the total daytime absorption. At night most of the absorption takes place in the interval from $75-85 \mathrm{~km}$. The criterion for "night" is met when the sun is more than $10^{\circ}$ below the horizon.

Assuming a fixed electron recombination coefficient for the different heights during night-time conditions, the variations in the riometer signal observed on the ground are due to variation in the particle precipitation flux. The energy spectrum of the precipitating energetic particles varies from one event to another, as well as during an event. Therefore we cannot expect to find a precise relationship between the radio absorption at different heights and the energy deposited at a certain height, but neither are the absorption variations entirely random. We will use the ground based night-time measurement performed by IRIS as a proxy for the energy deposited by precipitating particles in the upper-mesosphere near Andøya. We will discuss this assumption further in 


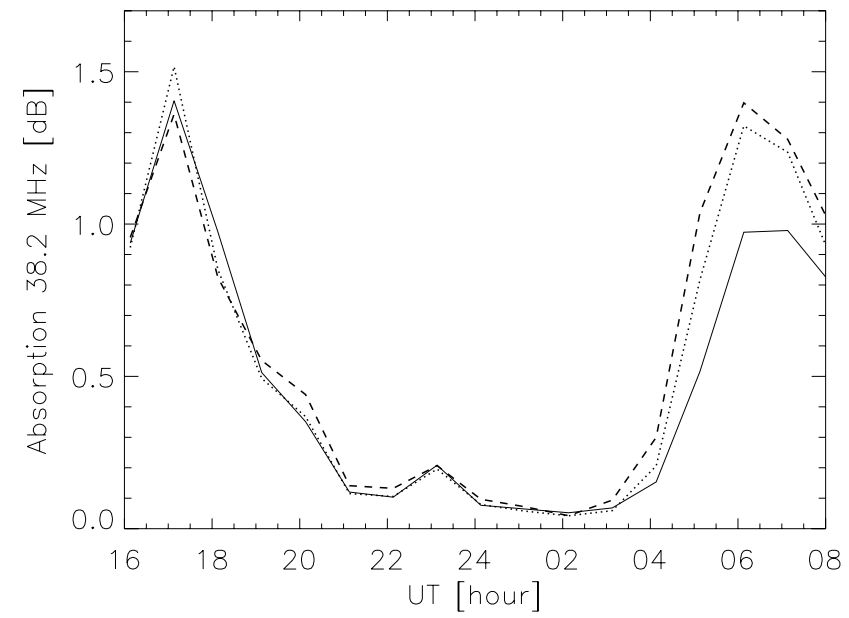

Fig. 3. The cosmic radio noise absorption measured by IRIS in beam 8 (solid line), 15 (dotted line), and 22 (dashed line) from 15:38 UT 21 January to 08:38 UT 22 January 2005.

Sect. 3.1, where we compare the absorption measurement to particle measurement performed by satellite borne detectors.

\subsection{The NOAA/POES satellites}

The NOAA/POES (National Oceanic and Atmospheric Administration/Polar Orbiting Environmental Satellites) are part of NOAA's operational weather satellite system. In January 2005 three satellites, NOAA 15, 16 and 17 were orbiting the Earth in a polar, sun-synchronous at $850 \mathrm{~km}$ altitude with a period of approximately $100 \mathrm{~min}$. Each satellite carries two types of particle sensors, Total Energy Detector (TED) and Medium Energy Proton and Electron Detector (MEPED) (Evans and Greer, 2000).

TED monitors electron and proton fluxes with energies in the range between 50 and $20000 \mathrm{eV}$, divided into 16 energy intervals. Four detectors (two electron and two proton detectors) are mounted in two groups, where one group is viewing radially outward from the Earth and the other group viewing at $30^{\circ}$. Every group has a proton detector and an electron detector. At auroral altitudes the first group, looks approximately along the field line and we refer to it as the vertical detector. We will use the electron fluxes measured in the energy intervals $2116-3075 \mathrm{eV}$, and $6503-9467 \mathrm{eV}$ from the vertical detector.

MEPED provides directional measurement of energetic particles. The instrument holds four directional solid-state detectors, pointing $9^{\circ}$ and $89^{\circ}$ to the local vertical. We refer to these detectors as the vertical and the horizontal detector, respectively. At high latitudes the vertical detector measures particles in the loss cone, while the horizontal detector measures particles that mirror or are close to mirroring at satellite altitude. The detectors have $\mathrm{a} \pm 15^{\circ}$ (total $30^{\circ}$ ) field of view. The protons are measured in six energy ranges: $30-80,80$ $250,250-800,800-2500,2500-6900$ and $>6900 \mathrm{keV}$. The electrons are measured in three energy channels: $>30,>100$, and $>300 \mathrm{keV}$.

\section{Observations}

On the 16 January a series of SPEs began causing periods of strong particle precipitation and geomagnetic disturbances as seen in the geomagnetic indicies in Fig. 1. In the declining phase of the so far hardest and most energetic SPE of Solar Clycle 23, the AE index reveals strong substorm activity. In particular, a large geomagnetic disturbance occurred at 21-22 January starting around 15:00-19:00 UT, reaching $\mathrm{AE}$ values of $2000 \mathrm{nT}$ and $K_{p}$ of 7-8. In this period we have $14 \mathrm{~h}$ of continuous nighttime temperature measurement with the Na lidar. In this period we also have continuous absorption measurement from IRIS. The three satellites, NOAA 15, 16 , and 17, passes through or near our region of interest. The first part of this section will be devoted to the observations concerning the particle precipitation, while the second part focuses on its possible influence on the temperature.

\subsection{Absorption and particle measurements}

Figure 3 shows the cosmic radio noise absorption measured by IRIS in beam 8,15 , and 22 from 16:00 UT 21 January to 08:00 UT 22 January 2005. At about 15:30 UT an absorption event starts. The three beams show more or less the same values, which indicates that the particle precipitation is fairly uniform over a large area. The absorption decreases to quiet values around 21:00 UT and it remains quiet till about 04:00 UT when a second absorption event starts. The absorption values in the different riometer beams indicate, however, that the precipitation has some localized variations. The solar elevation angle was more than $10^{\circ}$ below the horizon from the beginning of this period until about 06:45 UT on the 22 January. Consequently the criterion for nighttime conditions is fulfilled for most of this period. Even so, we wish to investigate if the changes in the absorption are actually due to changes in the particle precipitation and not an effect of changes in the electron recombination coefficient.

Using particle measurements from the vertical detectors on the TED and MEPED instruments onboard NOAA 15, 16, and 17 , we can detect the precipitating particles in and near our region of interest at several points in time. We project the particle measurement down to about $100 \mathrm{~km}$, and sort the measurement in a geomagnetic grid of $4^{\circ}$ latitudes and $10^{\circ}$ longitudes. To increase our data in the geomagnetic box that encloses Andøya, we interpolate linearly between the measurements from two of the satellites, e.g. NOAA 15 and 16, that passes the same geomagnetic latitude east and west of Andøya close in time. Global patterns of precipitating particle fluxes based on the NOAA satellites using interpolation techniques have been generated before by e.g. Fang et al. (2007). However, considering the interpolation, the time 

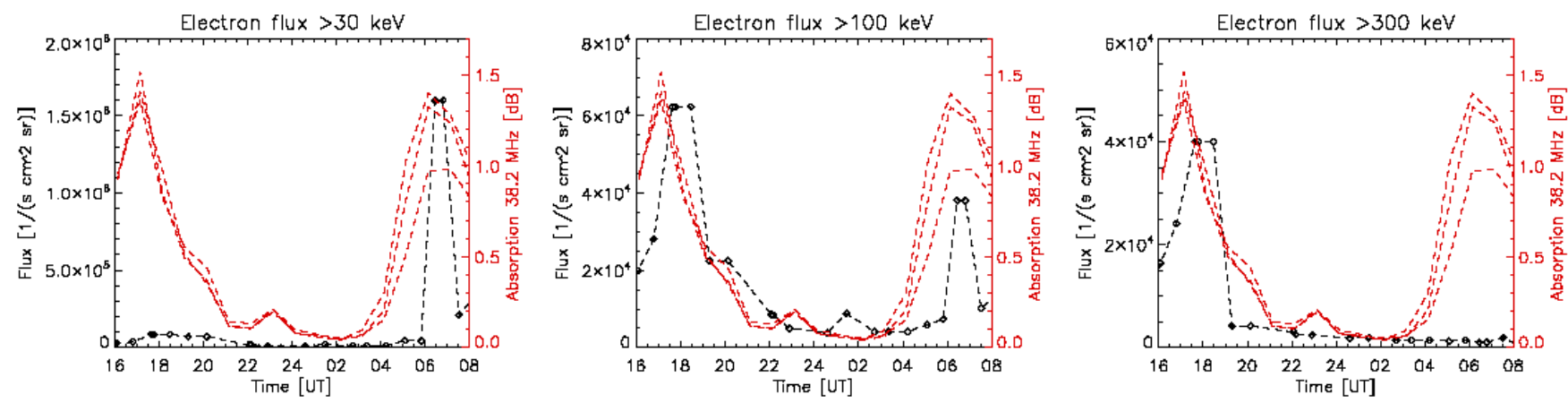

Fig. 4. The black diamonds show the electron flux in three energy channels, $>30 \mathrm{keV},>100 \mathrm{keV}$, and $>300 \mathrm{keV}$ above Andøya found by interpolating measurement from the MEPED vertical detector on NOAA 15, 16, and 17 on 21-22 January 2005. The red dashed lines show the cosmic radio noise absorption measured by IRIS in beam 8, 15, and 22.
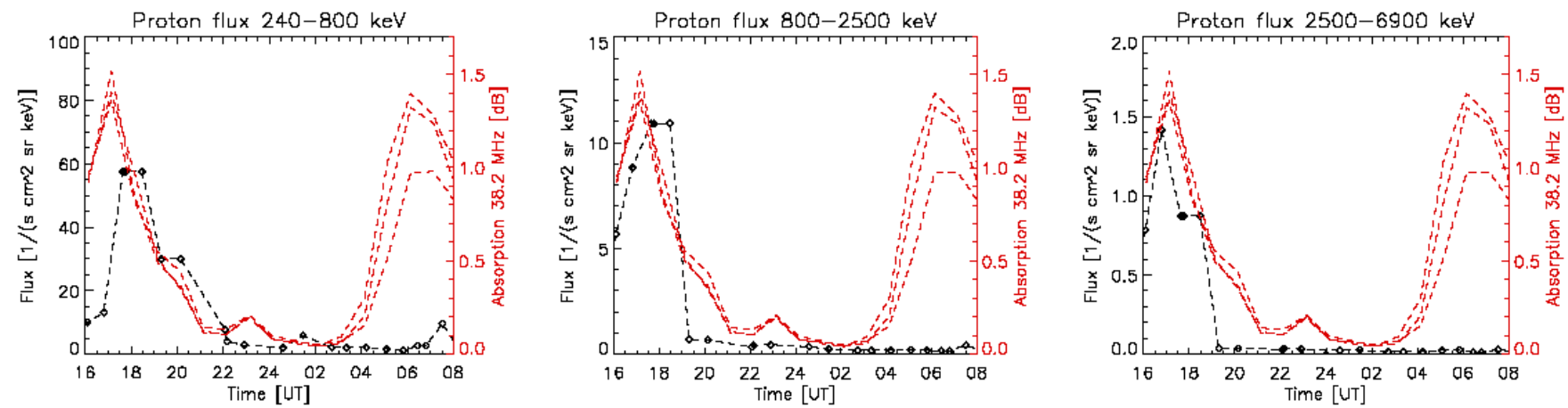

Fig. 5. The black diamonds show the proton flux in three energy channels, $240-800 \mathrm{keV}, 800-2500 \mathrm{keV}$, and $2500-6900 \mathrm{keV}$ above Andøya found by interpolating measurement from the MEPED vertical detector on NOAA 15, 16, and 17 on 21-22 January 2005. The red dashed lines show the cosmic radio noise absorption measured by IRIS in beam 8, 15 and 22.

differences between the satellite passes, and the coarse grid averaging out possible local effect, we do not expect a perfect correlation between IRIS and the fluxes retrieved from the NOAA satellites.

Figure 4 shows the electron flux in the energy channels $>30 \mathrm{keV},>100 \mathrm{keV}$, and $>300 \mathrm{keV}$ above Andøya using the interpolation method. The red dashed lines show the cosmic radio noise absorption measured by IRIS in beam 8,15 and 22. We find that both the absorption events are associated with increased electron flux. Focusing on the energy channel $>30 \mathrm{keV}$, we find the strongest electron flux during the second absorption event in the period 06:00-07:00 UT. The maximum of the electron flux fits well with the maximum in the absorption in this period. The first absorption event is also associated with an increase in the precipitating electron flux, but the electron flux is more than a factor 10 less than the electron flux at 06:00-07:00 UT. In the energy channels $>100 \mathrm{keV}$ and $>300 \mathrm{keV}$ we have the opposite relation between the two absorption event. The electron flux at these energies associated with the first absorption event is larger than during the second absorption event. In fact, we do not see any increase in precipitating electrons with energies $>300 \mathrm{keV}$ associated with the second absorption event.
Figure 5 shows the proton flux in the energy channels $240-$ $800 \mathrm{keV}, 800-2500 \mathrm{keV}$, and $2500-6900 \mathrm{keV}$. We find that there are more protons associated with the first absorption event compared to the second one in all the energy channels. The maximum in the proton flux in the three channels seems to fit fairly well with the first absorption maximum. However, we do not find increased proton fluxes coinciding with the second absorption event.

The particle measurements by the MEPED detectors could also indicate the hardness of the energy spectrum based on the ratio between the particle fluxes in the different energy channels. In Fig. 6 we have estimated a differential electron energy spectrum based on the electron flux in the vertical TED and MEPED detectors at two different times. The first point in time is associated with the first absorption event, while the other spectrum is based on observations during the second absorption event. The electron fluxes measured by the MEPED detector are integral fluxes. However, by combining the three channels, $>30 \mathrm{keV},>100 \mathrm{keV}$, and $>300 \mathrm{keV}$, we can derive the differential fluxes in the energy range $30-100 \mathrm{keV}$ and $100-300 \mathrm{keV}$. In other words, by combining these differential fluxes retrieved from MEPED fluxes and the fluxes measured in the two energy channels 

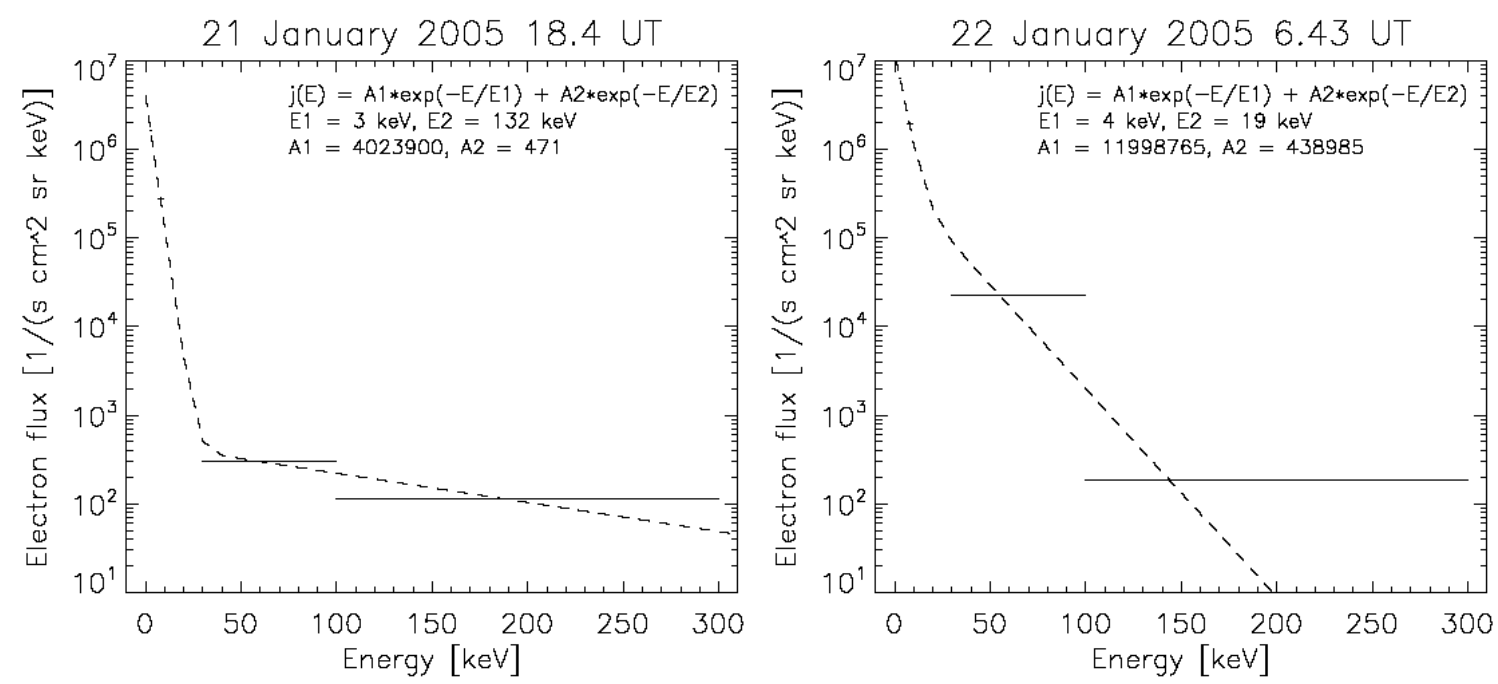

Fig. 6. The horizontal lines mark the electron flux in four channels $2.166-3.075 \mathrm{keV}, 6.503-9.467 \mathrm{keV}, 30-100 \mathrm{keV}, 100-300 \mathrm{keV}$ retrieved by interpolating measurement from the vertical TED and MEPED detectors on NOAA 15, 16, and 17 on 21-22 January 2005 at two selected times. The dashed line is the electron differential spectrum fitted to the flux in the four energy intervals.
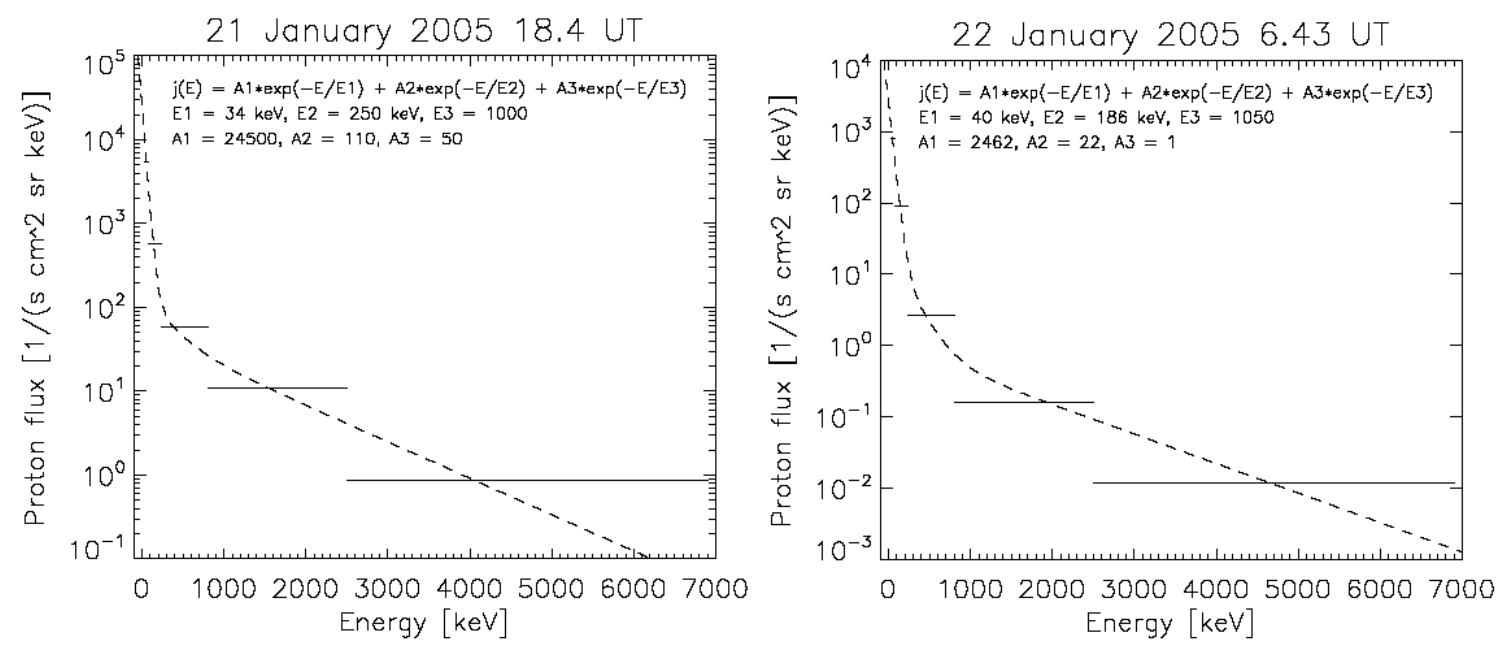

Fig. 7. The horizontal lines show the proton flux in five energy channels, $30-80 \mathrm{keV}, 80-240 \mathrm{keV}, 800-2500 \mathrm{keV}$, and $2500-6900 \mathrm{keV}$ above Andøya retrieved by interpolating measurement from the MEPED detectors on NOAA 15, 16, and 17 on 21-22 January 2005 at two selected times. The dashed line is the proton energy spectra fitted to the flux in five energy channels.

2116-3075 eV and 6503-9467 eV from TED, we have 4 differential energy channels with measured electron fluxes. The fluxes are fitted to a double exponential spectrum on the form:

$j(E)=A_{1} \cdot e^{-\frac{E}{E_{1}}}+A_{2} \cdot e^{-\frac{E}{E_{2}}}$

The characteristic energies, $E_{1}$ and $E_{2}$, and the factors $A_{1}$ and $A_{2}$ are determined so that the estimated differential spectrum reproduces the actual measurements when integrated over the respective energy intervals. We find a very hard energy spectrum associated with the first absorption event. As shown in Fig. 6 the characteristic energies are 4 and $132 \mathrm{keV}$.
Vertical incident electrons with the latter energy can penetrate the atmosphere down to almost $70 \mathrm{~km}$. Particles with characteristic energies associated with the second absorption event, will penetrate down to about $90 \mathrm{~km}$. The proton energy spectra based on five MEPED energy channels for the same points in time are shown in Fig. 7, but as a combination of three exponential functions.

Figure 8 shows the energy deposition height profiles based on the electron and proton spectra found in Figs. 6 and 7. The energy deposition by the electrons is found using a model called MANGLE, a computer code developed by University of Maryland based on the TANGLE code (Vondrak and 

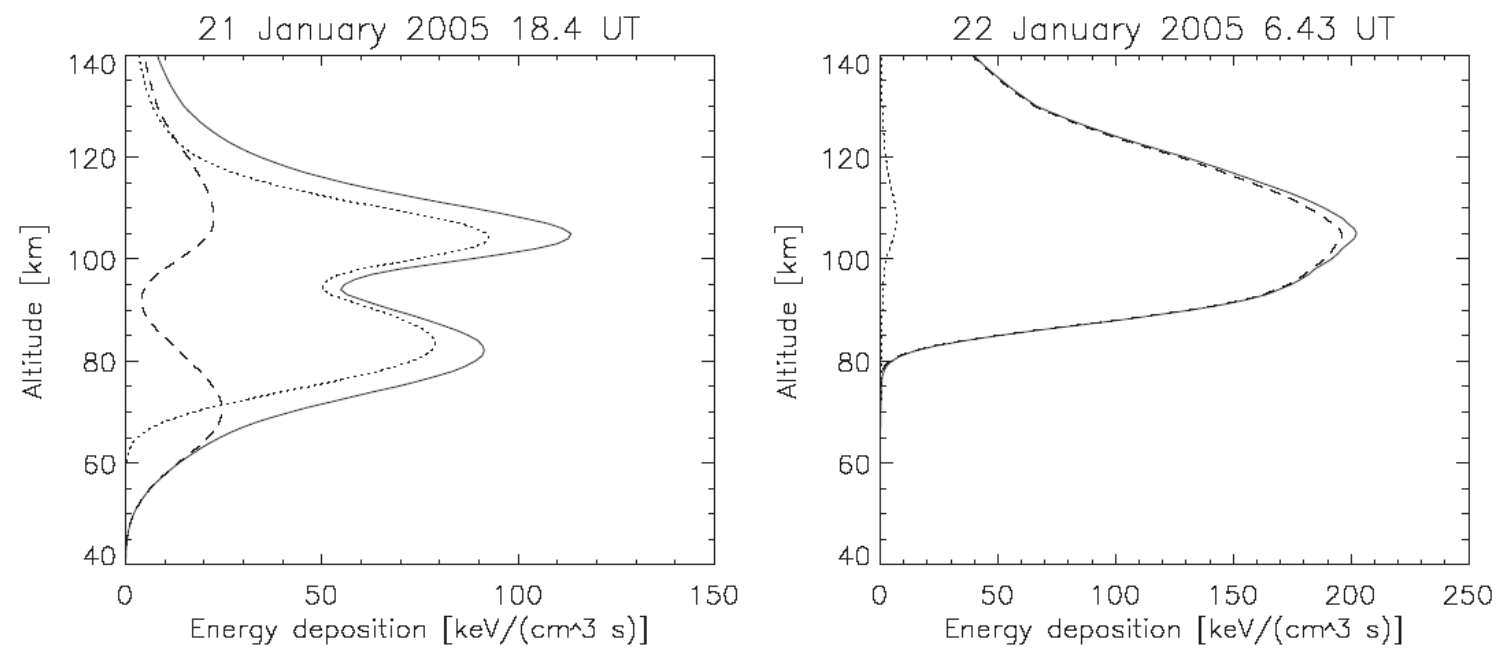

Fig. 8. Energy deposition height profiles estimated based on the electron and proton spectra found in Figs. 5 and 6 . The dashed line is the energy deposited by electrons, the dotted line is the energy deposited by protons, and the solid line is the total energy deposited by both protons and electrons.

Baron, 1976; Vondrak and Robinson, 1985). MANGLE uses the value of $35 \mathrm{eV}$ for the energy expended by the primary precipitation electrons for each ion-electron pair produced, which is in accordance with Rees (1989). The energy height profile for proton is calculated based on the simple formula presented in Mæhlum (1973):

$\frac{d E}{d z}=-236 \cdot E^{-0.78}$

where the energy loss, $d E / d z$, is given in units $\mathrm{MeV} \mathrm{cm}^{2} \mathrm{~g}^{-1}$. We assume that the precipitating protons are vertically incident. Atmospheric densities are estimated using MSIS-E-90. On 21 January 18:40 UT we find that the energy deposition rate has two local maxima, at $85 \mathrm{~km}$ and $105 \mathrm{~km}$. The energy deposition rate is dominated by protons, possibly solar protons based on their initial energy. However, on 22 January 06:43 UT we find a more typical energy deposition height profile peaking at one height, dominated by electrons with initial energies similar to auroral particles.

According to Fig. 8 we find an energy deposition rate of about $180 \mathrm{keV} \mathrm{cm}^{-3} \mathrm{~s}^{-1}$ at $95 \mathrm{~km}$ at 06:43 UT. Converted to SI units this corresponds to $2.88 \times 10^{-8} \mathrm{Jm}^{-3} \mathrm{~s}^{-1}$. The energy transfer to an individual neutral atmospheric particle per time at $95 \mathrm{~km}, \Delta E_{95 \mathrm{~km}} / \Delta t$, is approximately:

$\frac{\Delta E_{95 \mathrm{~km}}}{\Delta t}=\frac{2.88 \times 10^{-8} \mathrm{Jm}^{-3} \mathrm{~s}^{-1}}{0.22 \times 10^{20} \mathrm{~m}^{-3}} \approx 1.31 \times 10^{-27} \mathrm{Js}^{-1}$

where the number density at $95 \mathrm{~km}, 0.22 \times 1020 \mathrm{~m}^{-3}$, is found using MSIS. According to Rees et al. (1983) about half of the energy, $\Delta E_{\text {therm }}$, results in local atmospheric heating, which gives rise to a heating rate of approximately:

$\frac{\Delta T}{\Delta t}=\frac{2}{5} \frac{\Delta E_{\mathrm{therm}}}{\Delta t \cdot k} \approx 2.00 \times 10^{-5} \mathrm{Ks}^{-1} \approx 0.07 \mathrm{Kh}^{-1}$ assuming that the atmosphere at $95 \mathrm{~km}$ is an ideal diatomic gas. $k$ is the Boltzmann constant.

In summary, based on the particle fluxes retrieved from the particle detectors on the NOAA satellites the first absorption event observed by IRIS seem to be dominated by proton fluxes with initial energies similar to precipitating solar protons. The second absorption event observed by IRIS is associated with enhanced electron fluxes with energies similar to auroral electrons. Based on the electron and proton spectra from two selected periods in time we estimate the energy deposition height profiles, and the resulting heating rate at $95 \mathrm{~km}$ altitude.

\subsection{Temperature and absorption measurement}

On 21-22 January 2005 we have $14 \mathrm{~h}$ of night time measurements with the ALOMAR Weber Na lidar. Figure 9 shows contour plots based on hourly averaged temperatures measured in beam 1 and beam 2 . Beam 1 points $20^{\circ} \mathrm{W}$ of zenith, which corresponds to about $32 \mathrm{~km}\left(0.8^{\circ}\right.$ longitude $)$ at $90 \mathrm{~km}$ altitude. Beam 2 points $20^{\circ} \mathrm{E}$ of zenith. The contour plots reveal a complex temperature structure in our height interval of interest. In particular, we see a wavelike perturbation with a period of approximately $8 \mathrm{~h}$ and a vertical wavelength of about $10 \mathrm{~km}$. In the following we wish to analyze the gravity wave field in order to distinguish possible energetic particle precipitation effects from gravity waves effect.

In Figs. 10 and 11 we have fitted a 7.6-h wave at 85, 90, 95 and $100 \mathrm{~km}$. The $7.6( \pm 0.5)$ hour wave period is the most prominent period at 85 and $90 \mathrm{~km}$ in both beams (found by calculating Lomb Normalized Periodogram, and performing least squares fits of the data). At these altitudes it seems like a 7.6-h wave, with approximately $20-25 \mathrm{~K}$ amplitude could account for most of the temperature variations. At 95 and 


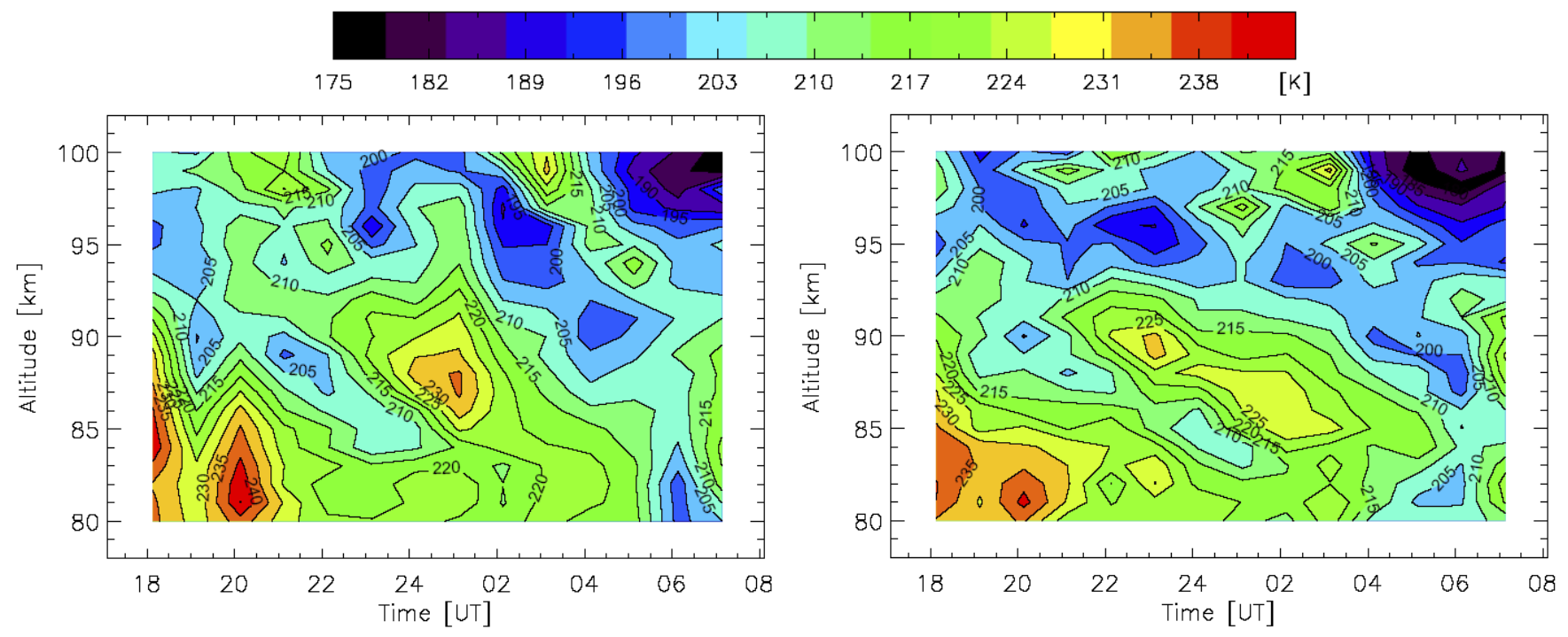

Fig. 9. Contour plots of hourly averaged temperatures from the ALOMAR Weber Na lidar on 21 and 22 January 2005 . Beam 1 (left): $20^{\circ} \mathrm{W}$ of zenith. Beam 2 (right): $20^{\circ} \mathrm{E}$ of zenith.

$100 \mathrm{~km}$ the 7.6-h wave is no longer that prominent, which could be due to e.g. dissipation of the wave, changes in the atmosphere's refractive index or background winds. The right panel in Figs. 9 and 10 shows the residual temperature after subtracting the 7.6-h wave. Looking at $90 \mathrm{~km}$, we do not find a temperature increase associated to the absorption event, marked with the red dashed lines. In fact, the largest temperature residual, found in beam 1 at the end of the first absorption event, is approximately $15 \mathrm{~K}$ cooler than the average temperature. The second absorption event is also associated with temperatures less than the mean value of the residual temperatures. At $95 \mathrm{~km}$ we do not see any obvious correlation between the temperature and the absorption events, while at $100 \mathrm{~km}$ we find temperatures below average in the periods of increased absorption in both beams.

Another way to eliminate the dominant temperature variations due to the 7.6-h wave could be to integrate the thermal energy over the vertical wavelength of the wave, assuming that the wave does not dissipate energy. Using the thermal energy instead of the temperature itself will average out the wave effect within the height interval. This will also reduce possible temperature effects from other possible waves with shorter vertical wavelengths than the 7.6-h wave. As mentioned above, we find the vertical wavelength of the 7.6-h wave to be about $10 \mathrm{~km}$. Figure 12 shows the height integrated energy at two height intervals, $80-90 \mathrm{~km}$, and 90 $100 \mathrm{~km}$, respectively. The atmospheric densities are found using MSIS-E-90. Since a wave also will cause variation in the background density, we have included an uncertainty of $3 \%$ in the density in addition to the temperature uncertainties. In the height interval $80-90 \mathrm{~km}$ it seems like the height integrated energy experiences a general decrease during our
$14 \mathrm{~h}$ of observations. However, we do not find any correlation between the absorption events and the height integrated energies in either of the two beams. The same conclusion applies to the height interval $90-100 \mathrm{~km}$.

\section{Discussion}

\subsection{Expected temperature changes}

Joule heating caused by ionospheric current systems and particle precipitation are prominent energy sources during geomagnetic disturbances. These heating sources can be highly localized in space and time. Peterherych et al. (1985) and Price and Jacka (1991) suggested that winds of several tens of $\mathrm{m} / \mathrm{s}$ at heights less than $110 \mathrm{~km}$ altitude could be triggered by particle heating and/or Joule heating. However, we do not find evidence of any immediate heating associated with energetic particle precipitation that could initiate vertical winds of this size. Our results are more in line with e.g. Offermann (1985). Offermann (1985) found daily averaged particle precipitation heating rates of approximately $0.1 \mathrm{~K} / \mathrm{h}(2.5 \mathrm{~K} / \mathrm{d})$ at $90 \mathrm{~km}$ during disturbed geomagnetic conditions, about the same size as we found at $95 \mathrm{~km}$ coinciding with the absorption events. The ionization caused by particle precipitation increases the Pedersen conductivity, which is proportional to the Joule heating. Banks (1979) and Roble et al. (1987) showed that locally mesospheric Joule heating at $90 \mathrm{~km}$ altitude could be substantial (1-12 K/d) for certain large SPEs. These heating rates are comparable to solar, infrared and chemical heating rates in the mesopause region (Berger and von Zahn, 1999). An increase in Joule and particle heating might be responsible for the observed heating of $\sim 2 \mathrm{~K} / \mathrm{d}$ 

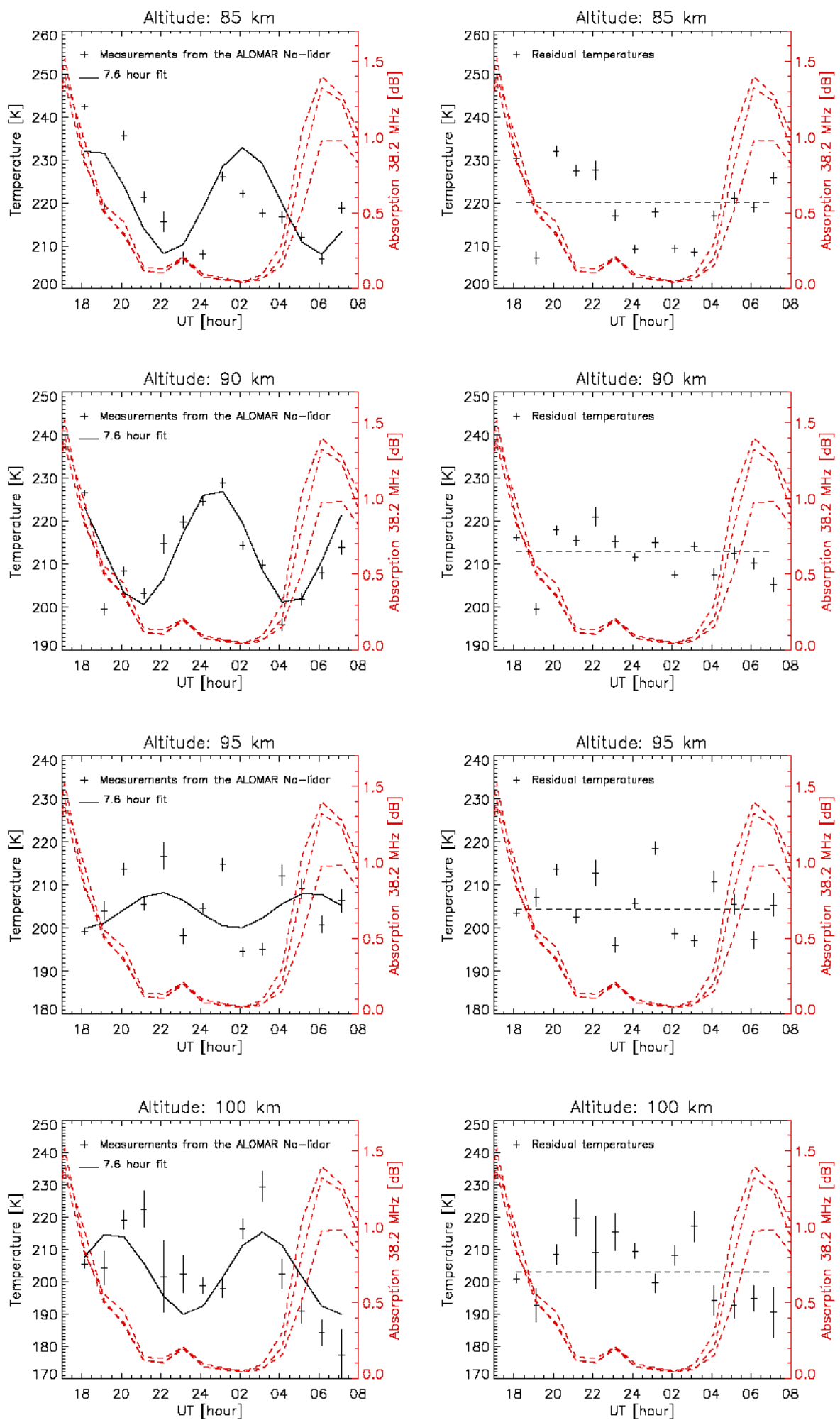

Fig. 10. The left column shows the hourly averaged temperatures, marked as crosses, from beam 1 the ALOMAR Weber Na lidar on $21-22$ January 2005 at 4 different heights. The solid black line shows a 7.6-h wave fit to the temperatures. The right column shows the temperature residuals when subtracting the wave fit. The red dashed lines show the cosmic radio noise absorption measured by IRIS in beam 8,15 and 22 . 

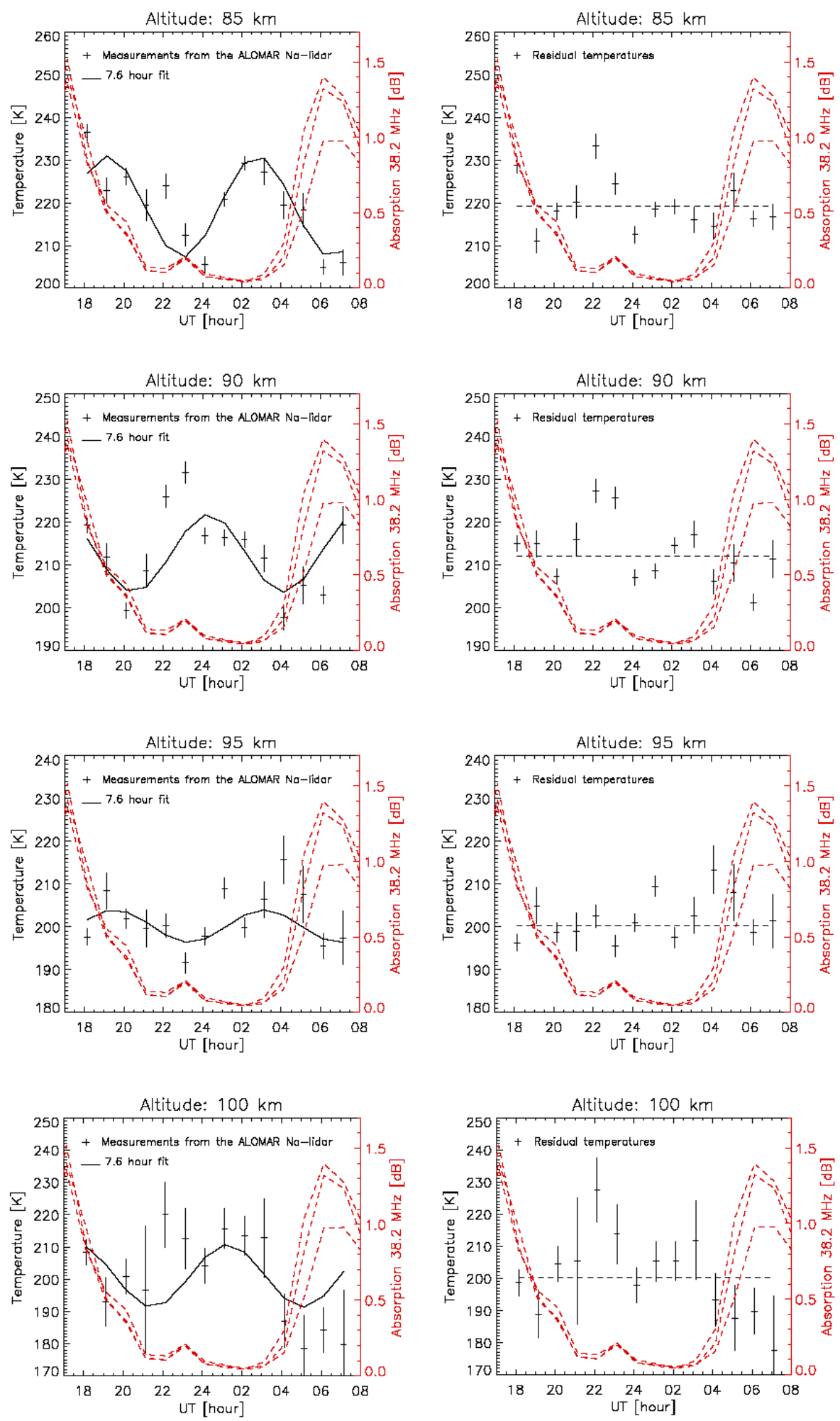

Fig. 11. The left column shows the hourly averaged temperatures, marked as crosses, from beam 2 in the ALOMAR Weber Na lidar on $21-22$ January 2005 at 4 different heights. The solid black line shows a 7.6-h wave fit to the temperatures. The right column shows the temperature residuals when subtracting the wave fit. The red dashed lines show the cosmic radio noise absorption measured by IRIS in beam 8 , 15 and 22. 

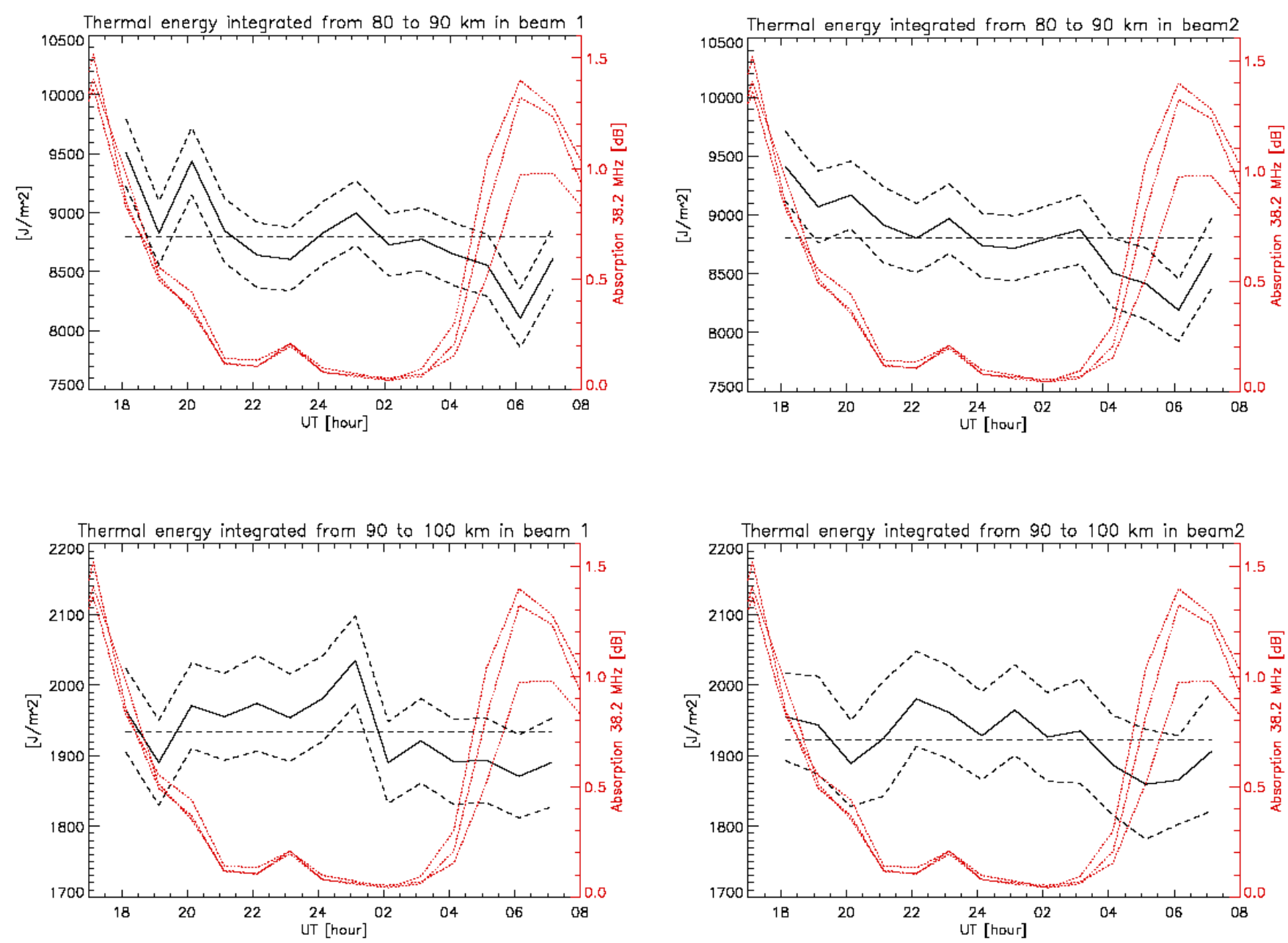

Fig. 12. The black solid line shows the thermal energy integrated from 80 to $90 \mathrm{~km}$ and 90 to $100 \mathrm{~km}$ in beam 1 (right column) and beam 2 (left column). The black dashed lines show the error estimate including 3\% density variation in addition to the temperature uncertainties. The red dashed lines show the cosmic radio wave absorption measured by IRIS in beam 8, 15, and 22.

by the Microwave Limb Sounder onboard the Aura satellite coinciding with the January 2005 SPEs (von Savigny et al., 2007). However, von Savigny et al. (2007) also covered the main phase of the January 2005 SPEs, and we might not expect to find similar heating rates in the declining phase of these events where our observations were done.

The particle precipitation does not only deposit energy, but also modifies the gas composition through ionization, dissociation and excitation. In particular, there has been found a strong correlation between the production of odd nitrogen, $\mathrm{NO}_{\mathrm{x}}$ and odd hydrogen $\mathrm{HO}_{\mathrm{x}}$ species and energetic particle precipitation (e.g. Crutzen et al., 1975; Swider and Kenesha, 1973; Jackman et al., 1980; Solomon et al., 1981; Sætre et al., 2004). These minor constituents reduce the ozone concentration through catalytic processes. Ozone is an important heating source in the mesopause region both as an absorber of solar radiation and through chemical reactions (Mlynczak and Solomon, 1993; Berger and von Zahn, 1999). There- fore any decrease in ozone ultimately results in less heating, in particular in the sunlit atmosphere, explaining the cooling below $80 \mathrm{~km}$ altitude associated with the October 1989 SPEs observed by Zadorozhny et al. (1994).

Pancheva et al. (2007) found a significant temperature drop of $\sim 25 \mathrm{~K}$ detected at $\sim 90 \mathrm{~km}$ altitude by the meteor radar at Andøya. The temperature decrease was in line with the enhancement of the proton fluxes associated with the SPEs and geomagnetic storms in late October 2003. Seppälä et al. (2004) showed significant ozone depletion in the Northern Hemisphere polar mesosphere, as seen by GOMOS/Envisat (Global Ozone Monitoring by Occultation of Stars/Environmental satellite) caused by the SPEs in October-November 2003. The ozone depletion could contribute to a cooling in this region. In contrast to Pancheva et al. (2007) we did not find a cooling effect in the upper mesosphere associated with the energetic particle precipitation. On the other hand, this could be due to the lack of sunlight 


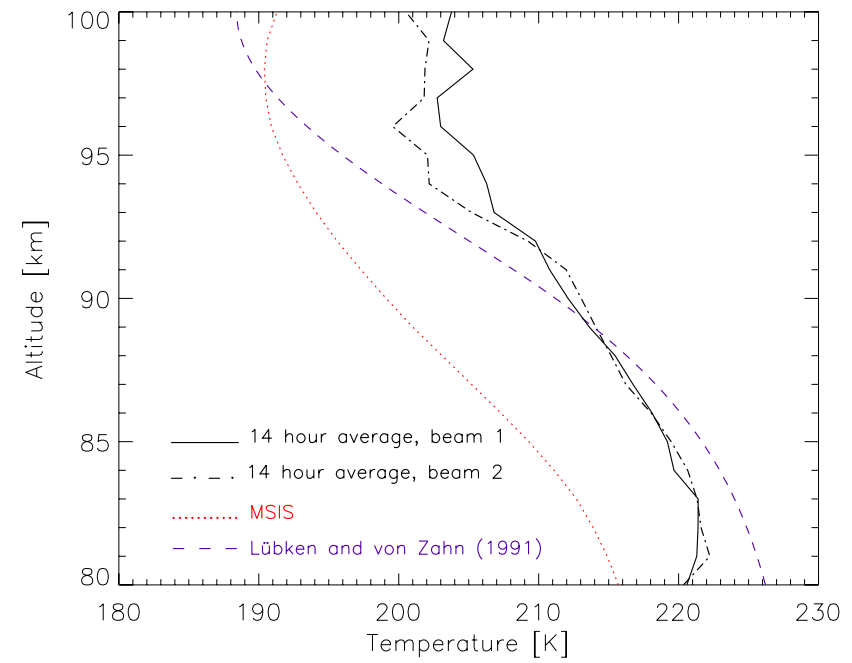

Fig. 13. The average temperature profiles based on $14 \mathrm{~h}$ of measurement in beam 1 (black solid line) and beam 2 (black dashed-dotted line) with the ALOMAR Weber Na lidar on 21-22 January 2005. The red dotted line shows the temperature predicted by the MSIS model. The blue dashed line shows the temperature climatology found by Lübken and von Zahn (1991) based on falling spheres above Andøya.

in the period we were measuring. Additionally, Pancheva et al. (2007) suggested that the heating via precipitating protons in the middle atmosphere could cause upwelling of the air cooling the upper mesospheric air adiabatically. As mentioned above, we did not find evidence for a heating that could be responsible for a potential upwelling at any of the observed heights. However, we cannot exclude the possibility of a potential heating or cooling effect occurring in the main phase of the January 2005 SPEs.

A cooling in the middle mesosphere as observed by Zadorozhny et al. (1994), could initiate a small downwelling. Model calculation by Jackman et al. (2007) suggested downward vertical winds of the order of $\mathrm{mm} / \mathrm{s}$. Even though the wind was relatively small it could cause an increased downward transport enhancing the atomic oxygen abundance. More atomic oxygen leads to more $\mathrm{O}-\mathrm{CO}_{2}$ collisions, which results in more excited $\mathrm{CO}_{2}$, and an enhanced infrared cooling rate (Jackman et al., 2007). The vertical transport could also change the $\mathrm{CO}_{2}$ abundance, as the $\mathrm{CO}_{2}$ concentration is not a constant fraction of the total atmospheric gas above $\sim 65 \mathrm{~km}$. However, a larger atomic oxygen concentration also strengthens the exothermic reaction $\mathrm{O}-\mathrm{HO}_{\mathrm{x}}$ and in that manner the chemical heating rate. The downward vertical wind could also cause adiabatic heating (Jackman et al., 2007).

All in all, energetic particles can cause both heating and cooling depending on which altitude we focus on and the specific conditions present. A sensitivity analysis made by Jackman et al. (2007) shows that the temperature modifica- tion is seasonally dependent. In the sunlit hemisphere, we might expect a heating at altitudes above $80 \mathrm{~km}$ and a cooling below $80 \mathrm{~km}$. However, they found little temperature modification in the winter hemisphere. In other words, we might not expect to see any temperature changes in the Northern Hemisphere during the January 2005 SPEs. The temperature increase reported by von Savigny et al. (2007) was observed in the Southern Hemisphere during this event. In addition, considering the size of the heating and cooling rates associated with SPEs and other energetic particle precipitation events, the discrimination of solar influences and influences by e.g. tidal and gravity waves, remains an almost impossible challenge. Analysing the temperature field on 21 and 22 January 2005 , we found a possible wave field with a period of $7.6 \mathrm{~h}$ and amplitude of $20-25 \mathrm{~K}$ at $90 \mathrm{~km}$. A potential heating of $10 \mathrm{~K} / \mathrm{d}$ would more or less be impossible to extract in a case study like ours.

\subsection{Time constants}

When looking for potential temperature changes associated with energetic particle precipitation we should also consider the time constants involved. Since radiative relaxation times in the upper mesosphere are of the orders of several days (Barabash et al., 2004) a potential temperature modification is expected to be rather stable and last several days after the event. As mentioned, the solar proton events in January 2005 started already on 16 January, which means that the temperature observed on 21 and 22 January could be influenced by days of increased particle precipitation and not just the precipitation coinciding with our measurement period. In Fig. 13 we have plotted the average temperature profiles based on our $14 \mathrm{~h}$ of measurements, the MSIS temperature profile, and the monthly mean based on the climatology found from falling spheres on Andøya (Lübken and von Zahn, 1991). We find that above $90 \mathrm{~km}$ our average temperature is larger than both the MSIS and the monthly mean falling sphere predictions. The deviation between the measured and predicted profiles increases with height, as we also would expect if the higher temperatures were due to e.g. Joule heating. However, we should interpret the comparison between the profiles with care because of the existence of a diurnal tidal wave or other long period waves, as our average temperature profile is only based on $14 \mathrm{~h}$.

\subsection{Long period waves}

When looking for possible temperature effects associated with the absorption events in Sect. 3.2 we identified a wave period of approximately $8 \mathrm{~h}$ at 85 and $90 \mathrm{~km}$, which we presumed was caused by tidal and gravity waves independent of the particle precipitation events. However, Rietveld et al. (1992) and Röttger (1994) have reported of similar wavelike structures in wind observations made by the EISCAT VHF radar during SPEs. They inferred a vertical wavelength 
of about $10 \mathrm{~km}$ and large amplitudes due to a wave with downward phase progression and $8-10 \mathrm{~h}$ period at altitudes of 60-80 km during three different SPEs in 1989 and 1990. Röttger (1994) points out that this period range, the large amplitude and the rather short vertical wavelength of $10 \mathrm{~km}$ is unlikely to be caused by the tidal variations below $75 \mathrm{~km}$ at high latitudes. They suggest that the waves could be excited by the thermodynamical and chemical effects created by solar protons precipitating the middle atmosphere.

In particular, Röttger (1994) focuses on the periodicity of the potential change in heating rates during SPEs. For instance there is strong dependence of the electron density on the solar zenith angle due to the formation of negative ions in darkness (Collis and Rietveld, 1990). This results in a diurnal and seasonal variation of the electron density below this altitude. The magnetospheric electric field also has a diurnal variation. The time scale of these changes is often consistent with a substantial $6-10 \mathrm{~h}$ spectral component in the electric field variations Röttger (1994). The combined effect of the varying electron density and electric field could perhaps cause noticeable variation in the Joule heating. Furthermore, the temporal variation in the SPEs itself often show quasiperiodicities of several hours to days, and is usually characterized by impulsive increases. Additionally, there could also be a change in the heating rates due to the production of $\mathrm{NO}_{\mathrm{x}}$ and $\mathrm{HO}_{\mathrm{y}}$, and the subsequent destruction of ozone.

\section{Summary and future work}

On 16 January 2005 began a series of SPEs, which ended with the so far hardest and most energetic SPE of Solar Cycle 23 on 20-22 January. In the declining phase of the SPE on 21-22 January 2005 coinciding with a large geomagnetic storm we have $14 \mathrm{~h}$ of continuous temperature measurement with the ALOMAR Na lidar, which according to the IRIS measurements includes 2 absorption events. Particle measurements from the three satellites, NOAA 15, 16 and 17 that pass through or near our region of interest confirms that the absorption events are probably due to particle precipitation and not due to changes in the electron recombination coefficient. This gave us an opportunity to search for possible temperature effects caused by local particle precipitation during a relatively strong geomagnetic event.

The temperature variations at 85 and $90 \mathrm{~km}$ is dominated by a $7.6 \mathrm{~h}$ downward propagating wave with vertical wavelength of approximately $10 \mathrm{~km}$. Assuming that the wave is due to tidal or gravity waves independent of the particle precipitation, we do not find any temperature modification that seems to be related to the absorption events. However, a potential temperature modification could be too small to isolate in a system of tides and gravity waves in a single case study. Above $90 \mathrm{~km}$ the measured average temperature is larger than predicted from both MSIS and the monthly mean climatology based on falling spheres, which could be due to energy deposited by particle precipitation and Joule heating prior to our measurement period. There is also a possibility that the identified wave phenomenon is an effect of the SPEs itself. Rietveld et al. (1992) and Röttger (1994) have reported of similar wavelike structures in wind observations made by the EISCAT VHF radar during SPEs, and found it conceivable that the wave could be exited by the effects of energetic particles precipitating the mesosphere.

Considering the size of the calculated heating rate we find it likely to be no immediate significant temperature effects of the particle precipitation in the upper mesosphere above Andøya on the 21-22 January 2005. If any measurable temperature effects take place, we find it most likely to be heating caused by particle precipitation over a longer time period prior to our measurement period. A wave with downward phase propagation would have to be triggered by a lower altitude source. Due to higher densities at lower altitudes the particle energy input would have to be significantly larger than measured in our case. However, taking into consideration that this paper only addresses one case and the different results reported on energetic particle precipitation and temperatures in the upper mesosphere, we choose to be prudent in making a general conclusion. Instead, we point out the need for future work and studies of simultaneous measurements of both the upper mesospheric temperatures and local energetic particle precipitation. First of all, we wish to address a similar study using the ALOMAR Na lidar in summer time, since earlier studies have shown a larger temperature effect due to strong particle precipitation in sunlit areas. Recent improvements of the lidar system have significantly improved our daylight measurements making this a strong possibility in the future. Independently of season, we should look for wave structures similar to the downward propagating wave of $\sim 8 \mathrm{~h}$ and short vertical wavelength both in geomagnetically quiet and disturbed periods using both lidar and other available instruments. An updated lidar climatology could also be useful when comparing temperature measurements retrieved in regions influenced by significant particle precipitation.

Acknowledgements. The ALOMAR Weber Na lidar is a cooperative effort of Colorado State University, NorthWest Research Associates/ Colorado Research Associates Division (NWRA/CoRA), the Norwegian Defence Research Establishment (FFI), the LeibnizInstitute of Atmospheric Physics, and Andøya Rocket Range. This research was supported by The Research Council of Norway projects 165573 and 170855 , by AFSOR under contracts F4962003-C-0045 and FA9550-06-C-0129, and by the NSF under grants ATM-0545262 and ATM-0436703.

Editor-in-Chief W. Kofman thanks A. Zadorozhny and another anonymous referee for their help in evaluating this paper. 


\section{References}

Arnold, K. S. and She, C.-Y.: Metal fluorescence lidar (light detection and ranging) and the middle atmosphere, Contemp. Phys., 44, 35-49, 2003.

Banks, P. M.: Observation of Joule and particle heating in the auroral zone, J. Atmos. Terr. Phys., 39, 179-193, 1977.

Banks, P. M.: Joule heating in the high-latitude mesosphere, J. Geophys. Res., 84, 6709-6712, 1979.

Barabash, V., Kirkwood, S., Feofilov, A., and Kutepov, A.: Polar mesosphere summer echoes during the July 2000 solar proton event, Ann. Geophys., 22, 759-771, 2004, http://www.ann-geophys.net/22/759/2004/.

Berger, U. and von Zahn, U.: The two-level structure of the mesopause: A model study, J. Geophys. Res., 104, $22083-$ 22 093, 1999.

Browne, S., Hargreaves, J. K., and Honary, B.: An imaging riometer for ionospheric studies, Electronics \& Communication Engeenering Journal, 7, 209-217, 1995.

Collis, P. N. and Rietveld, M. T.: Mesospheric observations with the EISCAT UHF radar during polar cap absorption: 1. Electron densities and negatice ions, Ann. Geophys., 8, 809-824, 1990, http://www.ann-geophys.net/8/809/1990/.

Crutzen, P. J., Isaksen, I. S. A., and Reid, G. C.: Solar Proton Events: Stratospheric Sources of Nitric Oxide, Science, 189, 457-459, 1975.

Evans, D. S. and Greer, M. S.: Polar orbiting environmental satellite space environment monitor 2: Instrument description and archive data documentation, NOAA Tech. Memo, 2000.

Fang, X., Liemohn, M. W., Kozyra, J. U., Evans, D. S., DeJong, A. D., and Emery, B. A.: Global $30-240 \mathrm{keV}$ proton precipitation in the 17-18 April 2002 geomagnetic storms: 1. Patterns, J. Geophys res., 112, A05301, doi:10.1029/2006JA011867, 2007.

Fricke, K. H. and von Zahn, U.: Mesopause temperatures derived from probing the hyperfine structure of the $\mathrm{D}_{2}$ resonance line of sodium by lidar, J. Atmos. Terr. Phys., 47, 499-512, 1985.

Hargreaves, J. K.: A new method of studying the relation between ionization rates and radio-wave absorption in polar-cap absorption events, Ann. Geophys., 23, 359-369, 2005, http://www.ann-geophys.net/23/359/2005/.

Heinrich, D., Blum, U., Williams, B., Vance. J., She, C.-Y., Singer, W., and Hoppe, U.-P.: Observations of wintertime mesopause temperatures with the ALOMAR Weber Na lidar during winter 2004/05, ESA SP-590, 133-137, 2005.

Jackman, C. H., Frederick, J. E., and Stolarski, R. S.: Production of odd nitrogen in the stratosphere and mesosphere: an intercomparison of source strengths, J. Geophys. Res., 85, 7495-7505, 1980.

Jackman, C. H. and McPeters, R. D.: The response of ozone to solar proton events during solar cycle 21: A theoretical interpretation, J. Geophys. Res., 90, 7955-7966, 1985.

Jackman, C. H., Ceriglia, M. C., Nielsen, J. E., Allen, D. J., Zawodny, J. M, McPeters, R.D., Douglass, A. R., Rosenfield, J. E., and Rood, R. B.: Two-dimensional and three-dimensional model simulations, measurements, and interpretation of the influence of the October 1989 solar proton events on the middle atmosphere, J. Geophys. Res., 100, 11 641-11 660, 1995.

Jackman, C. H., Roble, R. G., and Fleming, E. L.: Mesospheric dynamical changes induced by the solar proton events in October-November 2003, Geophys. Res. Lett., 34, L04812,
doi:10.1029/2006GL028328, 2007.

Kavanagh, A. J., Marple, S. R., Honary, F., McCrea, I. W., and Senior, A.: On solar protons and polar cap absorption: constraints on an empirical relationship, Ann. Geophys., 22, 1122-1147, 2004, http://www.ann-geophys.net/22/1122/2004/.

Krivolutsky, A. A., Klyuchnikova, A. V., Zakharov, G. R., Vyushkova, T. Yu., and Kuminov, A. A.: Dynamical response of the middle atmosphere to solar proton event of July 2000: Three dimensional model simulations, Adv. Space Res., 37, 16021613, doi:10.1016/j.asr.2005.05.115, 2006.

Kubo, K., Rottger, J., and Fukao, S.: Upper mesospheric temperature changes observed in PMSE and incoherent scatter during a strong polar cap absorption event, paper presented at 10th MST Radar Workshop, Inst. Geofis. del Peru, Lima, 2003.

Lübken, F.-J. and von Zahn, U.: Thermal structure of the mesopause region at polar latitudes, J. Geophys. Res., 96, 20 841-20 857,1991.

Mlynczak, M. G. and Solomon, S.: A detailed evaluation of the heating efficiency in the middle atmosphere, J. Geophys. Res., 98, 10517-10541, 1993.

Mæhlum, B. N.: Particle precipitation: Scattering and absorption, in: Cosmical Geophysics, Universitetsforlaget, 211-219, 1973.

Offermann, D.: The Energy Budget Campaign 1980: introductory review, J. Atmos. Terr. Phys., 47, 1-26, 1985.

Pancheva, D., Singer, W., and Mukhtarov, P.: Regional response of the mesosphere-lower thermosphere dynamics over Scandinavia to solar proton events and geomagnetic storms in late October 2003, J. Atmos. Sol. Terr., 69, 1075-1094, 2007.

Peterherych, S. G., Shepherd, S., and Walker, J. K.: Observation of vertical E-region neutral winds in two intense auroral arcs, Planet. Space. Sci., 33, 869-873, 1985.

Price, G. D. and Jacka, F.: The influence of geomagnetic activity on the upper mesosphere/lower thermosphere in the auroral zone. i. vertical winds, J. Atmos. Terr. Phys., 53, 909-922, 1991.

Rees, M. H., Emery, B. A., Roble, R. G., and Stamnes, K.: Neutral and ion gas heating by auroral electron precipitation, J. Geophys. Res., 88, 6289-6299, 1983.

Rees, M. H.: Physics and Chemistry of the Upper Atmosphere, Cambridge Univ. Press, 1989.

Reid, G. C., Solomon, S., and Garcia, R. R.: Response of the middle atmosphere to the solar proton events of august-december, 1989, Geophys. Res. Lett., 18, 1019-1022, 1991.

Rietveld, M. T., Collis, P. N., and Rottger, J.: Observations of atmospheric dynamics in the low- and middle-mesosphere with the EISCAT incoherent scatter rader during solar proton events, Adv. Space Res., 12, 1081-1084, 1992.

Roble, R. G., Emery, B. A., Garcia, R. R., Killeen, T. L., Hays, P. B., Reid, G. C., Solomon, S., Evans, D. S., Spencer, N. W., and Brace, L. H.: Joule heating in the mesosphere and thermosphere during the July 13, 1982, solar proton event, J. Geophys. Res., 92, 6083-6090, 1987.

Roble, R. G.: Energetics of the mesosphere and thermosphere, in: The Upper Mesosphere and Lower Thermosphere: A Review of Experiment and Theory, Geophys. Monogr. Ser., vol. 87, edited by: Johnson, R. M. and Killeen, T. L., 1-21, AGU, Washington D.C., 1995.

Rodger, C. J., Clilverd, M. A., Verronen, P. T., Ulich, T, Jarvis, M. J., and Turunen, E.: Dynamic geomagnetic rigidity cutoff 
variations during a solar proton event, J. Geophys. Res., 111, A04222, doi:10.1029/2005JA011395, 2006.

Röttger, J.: Solar proton events: a source for long period gravity waves in the polar mesosphere, in the Solar-terrestrial energy program: the initial results from STEP, 5, 473-476, Elsevier, 1994.

Seppälä, A., Verronen, P. T., Kyrölä, E., Hassinen, S., Backman, L., Hauchecorne, A., Bertaux, J. L., and Fussen, D.: Solar proton events of October-November 2003: Ozone depletion in the Northern Hemisphere polar winter as seen by GOMOS/Envisat, Geophys. Res. Lett., 31, L19107, doi:10.1029/2004GL021042, 2004.

She, C. Y., Vance, J. D., Williams, B. P., Krueger, D. A., Moosmüller, H., Gibson-Wilde, D., and Fritts, D. C.: Lidar studies of atmospheric dynamics near polar mesopause, EOS Trans. AGU, 83, 289-293, 2002.

Solomon, S., Rusch, D. W., Gérard, J.-C., Reid, G. C., and Crutzen, P. J.: The effect of particle precipitation events on the neutral and ion chemistry of the middle atmosphere II. Odd hydrogen, Planet. Space Sci., 29, 885-892, 1981.

Swider, W. and Kenesha, T.: Decrease of ozone and atomic oxygen in the lower mesosphere during PCA event, Planet. Space Sci., 21, 1969-1973, 1973.
Sætre, C., Stadsnes, J., Nesse, H., Aksnes, A., Petrinec, S. M., Barth, C. A., Baker, D. N., and Vondrak, R. R.: Energetic electron precipitation and the $\mathrm{NO}$ abundance in the upper atmosphere - a direct comparison during a geomagnetic storm, J. Geophys. Res., 109, A09302, doi:10.1029/2004JA010485, 2004.

Vance, J. D., She, C.-Y., and Moosmüller, H.: Continuouswave, all-solid-state, single-frequency $400-\mathrm{mW}$ source at $589 \mathrm{~nm}$ based on doubly resonant sum-frequency mixing in a monolithic lithium niobate resonator, Appl. Optics, 37, 4891-4896, 1998.

Vondrak, R. R. and Baron, M. J.: Radar measurements of latitudinal variation of auroral ionization, Radio Sci., 11, 939-946, 1976.

Vondrak, R. R. and Robinson, R.: Inference of high-latitude ionization and conductivity form AE-C measurements of auroral electron fluxes, J. Geophys. Res., 90, 7505-7512, 1985.

von Savigny, S., Sinnhuber, M., Bovensmann, H., Burrows, M.-B., and Schwartz, M.: On the dissapearance of noctilucent clouds during the January 2005 Solar proton events, Geophys. Res. Lett., 34, L04812, doi:10.1029/2006GL028106, 2007.

Zadorozhny, A. M., Kikhtenko, V. N., Kokin, G. A., Tuchkov, G. A., Tyutin, A. A., Chizhov, A. F., and Shtirkov, O. V.: Middle atmosphere response to the solar proton events of October 1989 using the result of rocket measurements, J. Geophys. Res., 99, $21059-21069,1994$. 